\title{
EFEKTIVITAS IKLAN TERHADAP KEPUTUSAN WISATAWAN MEMBELI TIKET PESAWAT DI TRAVELOKA.COM
}

\author{
Kristina Angelina Gultom ${ }^{1}$, NMS. Wijaya ${ }^{2}$, Ni Putu Eka Mahadewi ${ }^{3}$ \\ Email: kristinaangelina19@gamil.com¹, sofia_ipw@unud.ac.id², eka.mahadewi23@gmail.com³ \\ ${ }^{1,2,3}$ Program Studi S1 Industri Perjalanan Wisata, Fakultas Pariwisata, Universitas Udayana
}

\begin{abstract}
Abtract: This research was conducted to analyze the Effectiveness of Advertising on Tourist Decisions in Purchasing Flight Ticket on the Online Travel Agent Traveloka.com using the EPIC Model and Direct Rating Method (DRM) and its Effect on the Flight Ticket Purchase Decision partially and simultaneously. This research method uses data collection techniques in the form of observation, questionnaires, and literature study. The technique of determining the sample using a purposive sampling method. The data analysis technique used quantitative descriptive analysis and multiple linear regression analysis. The results of this study indicate that Traveloka.com advertising using the EPIC Model method in measuring the advertising communication approach has been effective in introducing products in the form of flight tickets with a value of 4,008 and the Direct Rating Method in measuring good value advertising messages in conveying messages with a value of 79.44. EPIC Model's multiple linear regression analysis on Purchasing Decisions has a positive effect with a significant value of 0.015 , the Direct Rating Method has a positive effect with a significant value of 0.003 , while simultaneously or simultaneously, the Effectiveness of Advertising on Purchasing Decisions has a positive and significant effect. Based on the results obtained, the effectiveness of advertising can have an influence on purchasing decisions made by buyers through advertisements that contain information about existing products.
\end{abstract}

\begin{abstract}
Abstrak: Penelitian ini dilakukan untuk menganalisis Efektivitas Iklan Terhadap Keputusan Wisatawan dalam Pembelian Tiket Pesawat di Online Travel Agent Traveloka.com menggunakan metode EPIC Model dan Direct Rating Method (DRM) dan Pengaruhnya Terhadap Keputusan PembelianTiket Pesawat secara parsial dan simultan. Metode penelitian ini menggunakan teknik pengumpulan data observasi, kuesioner, dan studi kepustakaan. Teknik penentuan sampel menggunakan metode purposive sampling. Teknik analisis data menggunakan analisis deskriptif kuantitatif dan analisis regresi linier berganda. Hasil dari penelitian ini menunjukan bahwa Iklan Traveloka.com menggunakan metode EPIC Model dalam mengukur pendekatan komunikasi iklan sudah efektif dalam memperkenalkan produk berupa tiket pesawat dengan nilai 4.008 dan Direct Rating Method dalam mengukur pesan iklan bernilai baik dalam menyampaikan pesan dengan nilai 79.44. Analisis regresi linier berganda EPIC Model terhadap Keputusan Pembelian berpengaruh positif dengan nilai signifikan sebesar 0.015, Direct Rating Method terhadap Keputusan Pembelian berpengaruh positif dengan nilai signifikan sebesar 0.003, sedangkan secara bersama-sama atau simultan Efektivitas Iklan terhadap Keputusan Pembelian berpengaruh positif dan bernilai signifikan. Berdasarkan hasil yang diperoleh, efektivitas iklan dapat memberikan pengaruh terhadap keputusan pembelian yang dilakukan oleh pembeli melalui iklan yang berisi suatu informasi mengenai produk yang ada.
\end{abstract}

Keywords: effectiviness advestisements, epic model, direct rating method, purchase decision, traveloka. 


\section{PENDAHULUAN}

Aktifitas pariwisata di Indonesia sudah mulai tumbuh dan berkembang, bahkan sudah menjadi sebuah trend dan gaya hidup sendiri bagi masyarakat. Dalam hal ini tidak hanya wisatawan mancanegara saja yang melakukan perjalanan wisata tetapi wisatawan domestik juga melakukan perjalanan wisata. Karakteristik wisatawan yang bepergian juga sangat beragam baik dalam usia, pekerjaan, asal dearah, tujuan bepergian, daerah tujuan wisata dan sebagainya. Semakin meningkatnya kunjungan wisatawan semakin banyak juga kebutuhan yang diperlukan. Dalam hal ini, kebutuhan pariwisata harus semakin cepat dalam pelayanannya dan menyesuaikan pesatnya perkembangan teknologi untuk memenuhi kebutuhan tersebut.

Pesatnya perkembangan ini dibuktikan dengan hasil survei wearesocial.com di tahun 2020 dapat diketahui bahwa sebanyak 272.1 juta penduduk Indonesia aktif menggunakan internet, sebanyak 338.2 juta menggunakan jaringan ponsel, 175.4 juta penduduk menggunakan internet, 160 juta penduduk aktif di media sosial. Sebesar $50 \%$ perempuan dan $50 \%$ laki-laki dari jumlah penduduk Indonesia. Sebanyak $1,1 \%$ terjadi perubahan tahunan pengguna media sosial dari jumlah penduduk Indonesia. Sebanyak $29,7 \%$ dari penduduk Indonesia yang menggunakan media sosial terdiri dari median age.

Fenomena ini membuat banyak pebisnis di bidang pariwisata mengembangkan sistem offline menjadi sistem online. Penjualan tiket pesawat secara online merupakan salah satu bisnis yang mengembangkan penjualan dari sistem offline menjadi sistem online. Kelebihan dalam melakukan pemesanan tiket pesawat melalui online travel agent sebagai berikut: a.) Konsumen dapat dengan mudah melakukan pemesanan secara fleksibel. Fleksibel yang dimaksud adalah dapat dilakukan dimana saja dan kapan saja. b.) Konseumen tidak perlu jauh-jauh pergi ke kantor biro perjalanan untuk memesan tiket pesawat. c.) Tiket dapat dipesan ke penyedia jasa yang akan melayani pemesanan konsumen selama 24 jam. d.) Dengan e-ticket konsumen tidak perlu membawa tiket kemana-mana. Dalam hal ini komunikasi yang dilakukan dalam pemasaran salah satunya ialah iklan. Iklan digunakan oleh perusahaan untuk memperkenalkan dan memperkuat citra dari produk mereka. Pesan yang disampaikan oleh iklan diharapkan dapat diterima masyarakat.

Berdasarkan data, pendapatan iklan berdasarkan media televise ditahun 2017 lebih tinggi dari tahun 2020, iklan melalui media ponsel ditahun 2020 lebih tinggi dari tahun 2017, iklan melalui media desktop ditahun 2017 lebih tinggi dari tahun 2020, iklan melalui media koran ditahun 2017 lebih tinggi dari tahun 2020, iklan melalui media outdoor ditahun 2017 lebih tinggi dari tahun 2020, iklan melalui media radio ditahun 2017 lebih tinggi dari tahun 2020, iklan melalui media radio ditahun 2017 lebih tinggi dari tahun 2020, iklan melalui media majalah ditahun 2017 lebih tinggi dari tahun 2020, iklan melalui media bioskop di tahun 2020 lebih tinggi dari tahun 2017.

Menggunakan iklan sebagai media untuk memperkenalkan produknya kepada masyarakat sangatlah efektif. Iklan haruslah kreatif, inovatif, dan efektif dalam menyampaikan pesan. Iklan haruslah tampil beda dengan iklan-iklan yang telah ada agar pesan yang disampaikan dapat diingat oleh masyarakat. Banyak agent perjalanan wisata yang menyediakan layanan pembelian tiket pesawat, berbagai jenis hotel dan harga tiket masuk sebuah destinasi melalui sebuah website. Salah satu website yang terkenal di Indonesia ialah Traveloka.com

Traveloka.com adalah perusahaan travel terkemuka di Asia Tenggara yang menyediakan berbagai kebutuhan perjalanan dalam satu platform. Traveloka.com menawarkan tiket pesawat, hotel, tiket kereta, paket pesawat + hotel, aktivitas \& rekreasi, produkproduk konektivitas, transportasi bandara dan bus. Traveloka.com bekerja sama dengan lebih dari 100 maskapai domestik dan internasional. Traveloka melayani lebih dari 200.000 rute penerbangan ke seluruh dunia. Traveloka.com pun memiliki inventori pemesanan akomondasi terbesar, bervariasi mulai dari hotel, apartemen, guest house, homestay, vila dan resor. Semua itu didukung oleh lebih dari 40 metode pembayaran untuk seluruh pelanggan di Indonesia, Thailand, Vietnam, Malaysia, Singapura, dan Filipina, serta customer service yang siap melayani selama 24 jam dalam Bahasa lokal. Hingga saat ini, Traveloka memiliki nilai valuasi mencapai 26,2 triliun 
rupiah. Total kunjungan ke website traveloka mencapai 16,5 juta orang tiap bulannya. Hal ini membuat Traveloka dijuluki sebagi perusahaan Unicorn bersama dengan Gojek dan Tokopedia yaitu perusahaan startup dengan valuasi diatas 1 milyar dollar.

Berdasarkan data, terlihat Traveloka.com menempati urutan ke 4 dengan nilai valuasi 3 US\$ Miliar di Mei 2021. Berdasarkan data Top Brand Index Situs Online Booking Tiket Pesawat dan Travel di Indonesia pada tahun 2015-2018 dimana Traveloka.com menempati urutan ke 1 secara berturut-turut, di posisi kedua adalah Tiket.com. berdasarkan survey pembelian tiket pesawat di tahun 2018. Perhitungan Top Brand Index dipengaruhi dari tiga variabel, yaitu: pangsa pikiran, pangsa pasar, pangsa komitmen dari konsumen dalam memilih suatu kategori produk.

Iklan yang efektif adalah iklan yang dibuat sedemikian rupa sehingga pesan yang disampaikan mudah dicerna dan dimengerti oleh masyarakat dan mengandung informasi yang benar sehingga mekanisme pasar berhasil bekerja untuk menjadikan pesan suatu iklan dapat tertanam secara mendalam dalam benak konsumen dan konsumen mencermatinya dengan sudut pandang yang benar. Efektivitas dalam kegiatan promosi memang dibutuhkan suatu perusahaan untuk memperkenalkan produk barang atau jasa yang baru dihasilkan kepada masyarakat secara luas. Ukuran yang menjadi dasar penilaian efektif dari iklan adalah pengaruhnya terhadap kesadaran, pengetahuan atau preferensi konsumen dan dampaknya pada penjualan. Menurut Gibson (1984) dalam Fajar (2012:23) efektivitas iklan suatu alat yang mengukur keberhasilan atau kegagalan suatu perusahaan terhadap kegiatan yang dilakukan perusahaan.

Melihat fenomena situs traveloka.com di Top Brand Index Situs Online Booking Tiket Pesawat dan Travel di Indonesia dimana Traveloka.com menempati urutan ke-1 secara berturut-turut dalam pembelian tiket pesawat dari banyaknya pesaing yang ada. Penulis tertarik untuk menganalisis efektivitas iklan yang dilakukan oleh Traveloka.com dalam mempengaruhi keputusan untuk membeli produk tiket pesawat, pengetahuan konsumen mengenai produk tiket pesawat di Traveloka.com, dan dampak iklan Traveloka.com dalam meningkatkan penjualan tiket pesawat. Penelitian ini menggunakan metode EPIC Model yang meliputi Empathy (empati), persuation (persuasi), Impact (dampak), dan Communication (komunikasi) untuk mengukur pendekatan komunikasi dan DRM (Direct Rating Method) dalam mengukur pesan iklan serta pengaruh efektivitas iklan terhadap keputusan pembelian tiket pesawat di Traveloka.com

\section{METODE}

Penelitian ini, akan meneliti website Traveloka.com yang merupakan situs pencarian harga tiket yang terlengkap dibandingkan situs agent perjalanan online yang lainnya. Penelitian ini juga menggunakan penyebaran kuesioner secara online dengan menggunakan google form sebagai alat dalam menyebarkan kuesioner. Adapun kuesioner dibagikan kepada wisatawan yang sudah pernah membeli tiket pesawat di online travel agent Traveloka.com.

Adapun variabel yang diteliti yaitu, pengukuran efektivitas iklan (EPIC Model dan Direct Rating Method) dan keputusan pembelian. EPIC Model dibagi menjadi empat dimensi yaitu, 1) Empathy, 2) Persusion, 3) Impact dan 4) Communication dan Direct Rating Method dibagi menjadi lima dimensi yaitu, 1) Attention, 2) Readthrougness, 3) Affection, 4) Cognitive dan 5) Behavior. Variabel keputusan pembelian dibagi dalam 5 sub-variabel yaitu, 1) Pengenalan masalah, 2) Pencarian informasi, 3) Evaluasi alternatif, 4) Keputusan pembelian dan 5) Perilaku pasca pembelian.

Teknik pengumpulan data yang digunakan dalam penelitian ini yaitu: 1) Observasi, 2) Kuesioner, teknik ini digunakan untuk memperoleh data dengan menyebarkan kuesioner kepada wisatawaan yang pernah mmebeli tiket pesawat di Traaveloka.com melalui google form. 3) Stidu kepustakaan, pada penelitian ini studi kepustakaan yang digunakan antaranya meliputi buku, jurnal, dan lain sebagainya. 4) Dokumentasi, padaa penlitian ini dokumentasi berupa gambar dari iklan Traveloka.com

Teknik Penentuan dan teknik pengambilan sampel, dalam penelitian ini metode yang digunakan untuk melakukan pengambilan sampel yaitu dengan menggunakan metode Non-probability 
Sampling. Adapun teknik Non-probability Sampling yang digunakan yaitu teknik Purposive Sampling. Reponden yang dipilih untuk dijadikan sampel adalah orang yang pernah membeli tiket pesawat di Traveloka.com, serta mengetahui kegiatan promosi dari Traveloka.com dan bersedia mengisi kuesioner. Penentuan jumlah sampel penelitian menggunakan teori Suparto (2006) dengan jumlah indicator x 5 sampai 10, maka berdasrkan rumus diatas jumlah sampel yang dibutuhkan ialah 24 x $5=120$. Kuesioner yang dibuthkan yaitu sebanyak 120 responden.

Teknik analisis data yang digunakan dalam penelitian ini adalah analisis deskriptif kuantitatif. Perhitungan skala likert digunakan untuk mengelola data untuk untuk mengukur efektivitas iklan terhadap keputusan pembelian. Metode ini meliputi 1) Uji validasi, 2) Uji reliabilitas 3) EPIC Model, 4) Direct Rating Method, 5) Uji regresi berganda, 6) Koefisien Determinasi

\section{HASIL DAN PEMBAHASAN}

Traveloka adalah perusahaan yang menyediakan layanan pemesanan tiket pesawat dan hotel secara daring dengan focus perjalanan domestik di Indonesia. Traveloka memiliki basis operasional di Jakarta. Pesusahaan didirikan pada tahun 2012 oleh Ferry Unardi, Derianto Kusuma, dan Albert. Pada awal konsepnya Traveloka berfungsi sebagai mesin pencari untuk membandingkan harga tiket pesawat dari berbagi situs lainnya. Pada pertengahan tahun 2013 Traveloka kemudian berubah menjadi situs reservasi tiket pesawat dimana pengguna dapat melakukan pemesanan di situs resminya. Pada bulan Maret 2014, Ferry Unardi menyatakan bahwa Traveloka akan segera masuk ke bisnis reservasi kamar hotel. Pada bulan Juli 2014, jasa pemsanan hotel telah tersedia di situs Traveloka.

Traveloka sendiri saat ini berkembang sebagai salah satu startup sukses di Indonesia. Sejak didirikan pada tahun 2012, Traveloka rintisan Ferry Unardi terus mendapatkan suntikan dana dari berbagai investor untuk menggembangkan bisnisnya. Bisnisnya tidak hanya melayani penjualan tiket pesawat saja namun sudah merabah jasa reservasi hotel, tiket kereta api, top up pulsa, dan tiket event. Adapun Visi dari Traveloka adalah: a) Menjadikan traveling lebih mudah, cepat dan menyenangkan melalui teknologi. b) Menjadi salah satu perusahaan Biro Perjalanan Wisata (Agent Perjalanan) terbaik di Indonesia. c) Berkonstribusi didalam meningkatkan insustri pariwisata dan transportasi/perjalanan di Indonesia. Misi dari Traveloka adalah: a) Selalu menghadirkan produk-produk layanan terbaik. b) Memberikan kemudahan dan kenyaman bagi setiap pelanggan. c) Secara terus menerus meningkatkan kemampuan SDM dan infrastruktur perusahaan sehingga dapat memberikan pelayanan yang terbaik kepada seluruh pelanggannya. d) Menjalin dan meningkatkan kerja sama dengan semua mitra usaha, baik domestik dan Internasional.

\section{Karakteristik Pengguna Traveloka.com}

Karakteristik wisatawan yang membeli tiket pesawat di Traveloka.com dapat diketahui bahwa 120 responden terbanyak berasal dari Pulau Jawa sebesar 42\%. Adapun kategori ini sesuai dengan hasil sensus penduduk di Indonesia 2020 bahwa pulau Jawa memiliki penduduk terbesar dengan nilai $56,10 \%$ atau 151,59 juta penduduk di Indonesia. Berdasarkan jenis kelamin terbanyak adalah Perempuan sebesar $62 \%$. Dengan demikian, wisatawan perempuan lebih mendominasi menggunakan traveloka.com.

Berdasarkan usia terbanyak adalah 15-34 tahun sebesar $82 \%$. Adapun kategori ini usia dibawah 34 tahun lebih produktif menggunakan internet dan melakukan perjalananan wisata dibandingkan usia diatas 34 tahun. Berdasarkan status terbanyak adalah Belum Menikah sebesar 67\%. Adapun kategori ini, wisatawan yang berstatus belum menikah lebih mempunyai banyak waktu luang untuk menggunakan internet dan berpergian dari pada yang sudah terikat dengan status pernikahan. Berdasarkan pendidikan terakhir wisatawan yang membeli tiket pesawat di traveloka.com terbanyak pada tingkat SMA sebesar $42 \%$. Adapun kategori ini sesuai dengan hasil sensus penduduk di tahun 2020 terdapat 141.31 jiwa yang terdiri dari generasi $\mathrm{Z}$ perkiraan usia 8-23 tahun dan generasi milenial perkiraan usia 2439 tahun.

Berdasarkan sumber infomasi yang didapatkan sebanyak $62 \%$ mengetahui 
traveloka.com melalui iklan di internet. Adapun kategori ini sumber informasi berdasarkan media ini sesuai dengan survei yang dilakukan di tahun 2020 berdasarkan databoks.com dimana media ponsel mimiliki nilai yang tinggi dibanding media yang lain, data ini juga sesuai dengan jumlah pengguna internet di tahun 2020 berdasarkan wearesocial.com terdapat 175.4 juta penduduk Indonesia yang menggunakan layanan internet.

Hasil analisis regresi berganda digunakan untuk mengetahui pengaruh pengaruh variabel EPIC Model (X1), dan DRM (X2) terhadap variabel keputusan pembelian (Y). Adapun persamaan Analisis Regresi Berganda pada penelitian ini sebagai berikut: $Y=8.414+0.252 X_{1}+$ $0.213 X_{2}+e$, dengan demikian menunjukan bahwa terdapat pengaruh secara positif dan signifikan secara simultan antara variabel EPIC Model dan DRM terhadap keputusan pembelian tiket pesawat di traveloka.com. Dengan demikian, dapaat dijelaskan bahwa EPIC Model berpengaruh terhadap keputusan pembelian sebesar 0.252. DRM berpengaruh terhadap keputusan pembelian sebesar 0.213 .

Koefisien korelasi digunakan untuk mengetahui kuat dan lemahnya tingkat atau derajat hubungan korelasi antara EPIC Model dan DRM terhadap keputusan pembelian, diketahui bahwa nilai $\mathrm{R}$ square 0.585 artinya bahwa efektivitas iklan dari traveloka.com memberikan pengaruh $58.5 \%$ terhadap keputusan pembelian tiket pesawat di traveloka.com, sedangkan sisanya $41.5 \%$ merupakan variabel lain yang tidak diteliti oleh peneliti.

Tabel 1. EPIC Model

\begin{tabular}{llll}
\hline No. & Dimensi & Nilai & Keterangan \\
\hline 1. & Empathy & 4.085 & Efektif \\
\hline 2. & Persuasion & 3.925 & Efektif \\
\hline 3. & Impact & 3.995 & Efektif \\
\hline 4. & Communication & 4.03 & Efektif \\
\hline EPIC & rate & 4.008 & Efektif
\end{tabular}

Sumber: Data Diolah, 2020.

Analisis efektivitas iklan berdasarkan EPIC Model dapat diketahui bahwa nilai dari dimensi Empathy pada iklan traveloka.com sebesar 4,085 dan termasuk dalam kategori efektif. Hasil analisis dimensi Persuasion pada iklan traveloka.com menunjukkan bahwa iklan tersebut termasuk dalam kategori efektif dengan nilai sebesar 3,925. Hasil analisis dimensi Impact pada iklan traveloka.com dengan nilai sebesar 3,995 menunjukkan bahwa iklan tersebut termasuk dalam kategri efektif. Hasil analisis dimensi Communication pada iklan traveloka.com menunjukan bahwa iklan tersebut efektif dengan nilai sebesar 4,03. Berikutnya hasil dari masing-masing dimensi EPIC di rata-ratakan menjadi EPIC rate dengan hasil akhir sebesar 4,008 yang termasuk dalam kategori efektif. Hal ini memeperlihatkan bahwa kinerja iklan dari traveloka.com yang disampaikan mudah dicerna sehingga konsumen dapat mencermati informasi tersebut.

Tabel 2. Direct Rating Method (DRM)

\begin{tabular}{lllll}
\hline No & Faktor & Nilai & $\begin{array}{l}\text { Skala } \\
\text { Direct } \\
\text { Rating }\end{array}$ & Keterangan \\
\hline 1. & Attention & 3.705 & 14.82 & Efektif \\
\hline 2. & $\begin{array}{l}\text { Read } \\
\text { Througness }\end{array}$ & 4.05 & 16.2 & Efektif \\
\hline 3. & Cognitive & 3.99 & 15.96 & Efektif \\
\hline 4. & Affection & 3.98 & 15.92 & Efektif \\
\hline 5. & Behaviour & 4.135 & 16.54 & Efektif \\
\hline Direct Rating Rate & & 79.44 & Baik \\
\hline
\end{tabular}

Sumber: Data Diolah, 2020.

Analisis efektivitas iklan berdasarkan Direct Rating Method dapat diketahui bahwa nilai dari faktor Attention termasuk kategori efektif dengan nilai 3.705. Hasil dari faktor Read Througness termasuk kategori efektif dengan hasil 4.05. Hasil dari Cognitive termasuk kategori efektif dengan nilai 3.99. Hasil dari faktor Affection dan behavior secara berturut dengan nilai 3.98 dan 4.135 termasuk dalam kategori efektif. Setiap nilai yang ada dikonversikan ke skala rumus direct rating methor dengan hasil faktor Attention sebesar 14.82, faktor Read Througness sebesar 16.2, hasil faktor Cognitive sebesar 15.96 faktor Affection sebesar 15.92, dan hasil faktor behavior sebesar 16.54. Selanjutnya hasil dari seluruh faktor dijumlahkan menjadi Direct Rating dengan hasil sebesar 79.44 yang dika dimasukan ke dalam rentang skala direct rating maka iklan traveloka.com termasuk ke dalam kategori iklan baik. 
Analisis pengaruh EPIC Model terhadap keputusan pembelian tiket pesawat melalui Traveloka.com menunjukkan bahwa EPIC Model (X1) berpengaruh positif dan signifikan terhadap keputusan pembelian (Y) tiket pesawat. Dengan nilai signifikasi sebesar sebesar $0.015<0.05$, sedangkan $t_{\text {hitung nilainya }}$ sebesar $2.467>t_{\text {tabel }}$ sebesar 1.980. Oleh karena itu, variabel EPIC Model merupakan salah satu faktor yang dapat mempengaruhi wisatawan untuk mengambil keputusan terhadap pembelian sebuah tiket pesawat. Analsiis pengaruh Direct Rating Method menunjukan bahwa Direct Rating Method (X2) berpengaruh positif dan signifikan terhadap keputusan pembelian (Y) tiket pesawat. Dengan nilai signifikasi sebesar $0.003<0.05$, sedangkan $t_{\text {hitung nilainya sebesar } 3.043>}$ $t_{\text {tabel }}$ sebesar 1.980. Oleh karena itu, variabel Direct Rating Method merupakan salah satu faktor yang dapat mempengaruhi wisatawan untuk mengambil keputusan terhadap pembelian sebuah tiket pesawat.

Analsisis Efektivitas Iklan secara simultan terhadap keputusan pembelian tiket pesawat melalui Traveloka.com dapat diinterprestasikan sebagai berikut, efektivitas iklan dalam penelitian ini mencakup 2 variabel yaitu EPIC Model dan Direct Rating Method. Kedua variabel ini memiliki pengaruh yang positif dan signifikan terhadap keputusan pembelian tiket pesawat di traveloka.com berdasarkan hasil pengujian yang telah dilakukan. Hasil pengujian menunjukan bahawa nilai sig untuk pengaruh variabel $\mathrm{X}$ secara simultan berpengaruh terhadap $\mathrm{Y}$ adalah sebesar $0.000<0.05$, sedangkan untuk $F_{\text {hitung }}$ diperoleh sebesar 82.481 dan untuk $F_{\text {tabel }}$ sendiri diperoleh nilai sebesar 2.68. Dari hasil tersebut maka $\mathrm{F}_{\text {hitung }}(82.481)>\mathrm{F}_{\text {tabel }}$ (2.68). Berdasarkan hal tersebut, dapat disimpulkan bahwa EPIC Model (X1) dan Direct Rating Method (X2) memiliki pengaruh secara simultan terhadap Keputusan Pembelian (Y) tiket pesawat melalui online travel agent traveloka.com.

Berdasarkan hasil yang didapatkan, maka dapat disimpulkan bahwa efektivitas iklan dapat meberikan pengaruh terhadap keputusan pembelian yang dilakukan oleh pembeli melalui iklan yang berisi suatu informasi mengenai produk yang ada, hal ini sejalan dengan yang dikemukan bahwa periklanan yang efektif yaitu apabila mencapai tujuan-tujuan yang ingin dicapai oleh pengiklan (Shimp, 2003).

\section{SIMPULAN DAN SARAN Simpulan}

Karakteristik wisatawan berdasarkan daerah asal sebesar $42 \%$ atau 50 orang berasal dari pulau Jawa. Berdarkan jenis kelamin sebanyak $62 \%$ atau 74 orang adalah perempuan. Berdasarkan usia sebesar $82 \%$ atau 99 orang adalah usia 15-34 tahun. Berdasarkan status sebanyak $67 \%$ atau 80 orang adalah belum menikah. Berdasarkan pendidikan terakhir sebanyak $42 \%$ atau 50 orang adalah tingkat SMA. Beradasarkan sumber informasi sebanyak $62 \%$ atau 79 orang mengetahui traveloka.com melalui iklan di internet.

Analisis efektivitas iklan dengan EPIC Model diketahui bahwa nilai dari dimensi Empathy sebesar 4,085 termasuk kategori efektif. Hasil dimensi Persuasion sebesar 3,935 termasuk kategori efektif. Hasil dimensi Impact sebesar 3,995 termasuk dalam kategori efektif. Hasil dimensi Communication sebesar 4,03 termasuk kategori efektif. Berikutnya hasil dari setiap masing-masing dimensi EPIC dirata-ratakan menjai EPIC rate dengan hasil 4,008 dan termasuk kategori efektif. Analisis efektivitas iklan dengan Direct Rating Method (DRM) dikategorikan dalam iklan baik dengan hasil sebesar 79.44 dimana diketahui bahwa nilai dari faktor Attention termasuk dalam kategori efektif dengan nilai 3,705. Hasil dari faktor Read Througness termasuk dalam kategori efektif dengan hasil 4,05. Hasil faktor Cognitive termasuk kategori efektif dengan nilai 3,99. Hasil faktor Affection termasuk kategori efektiv dengan nilai 3,98. Hasil faktor Behaviour termasuk kategori efektif dengan nilai 4,135.

Pada penelitian ini, berdasarkan hasil ditemukan pengaruh variabel EPIC Model (X1) terhadap keputusan pembelian (Y) memiliki signifikan sebesar $0.015<0.05$, sedangkan $t_{\text {hitung nilainya sebesar } 2.467>}$ $t_{\text {tabel }}$ sebesar 1.980. Maka berdasarkan nilai tersebut dapat disimpulkan bahwa 
hipotesis pertama diterima karena terdapat pengaruh antara EPIC Model (X1) terhadap Keputusan Pembelian (Y). Adapun untuk variabel Direct Rating Method (X2) memiliki nilai signifikasi sebesar $0.003<0.05$, sedangkan $t_{\text {hitung nilainya }}$ sebesar $3.043>t_{\text {tabel }}$ sebesar 1.980. Maka berdasarkan nilai tersebut dapat disimpulkan bahwa hipotesis kedua diterima karena terdapat pengaruh antara Direct Rating Method (X2) terhadap Keputusan Pembelian (Y). Berdasarkan hasil yang ditemukan pengaruh variabel Efektivitas Iklan (EPIC Model dan Direct Rating Method) secara simultan berpengaruh terhadap keputusan pembelian (Y) adalah sebesar $0.000<0.05$, sedangkan untuk $\mathrm{F}_{\text {hitung }}$ diperoleh sebesar 82.481 dan untuk $F_{\text {tabel }}$ sendiri diperoleh nilai sebesar 2.68. Dari hasil tersebut maka $\mathrm{F}_{\text {hitung }}$ (82.481) $>\mathrm{F}_{\text {tabel }}$ (2.68), maka dapat disimpulkan bahwa EPIC Model (X1) dan Direct Rating Method (X2) memiliki pengaruh secara simultan terhadap Keputusan Pembelian (Y) tiket pesawat di online travel agent Traveloka.com.

\section{Saran}

Berdasarkan pembahasan pada penelitian ini, maka peneliti mencoba memberikan saran-saran. Adapun saran-saran yang dapat diberikan berdasarkan hasil penelitian, diketahui bahwa secara keseluruhan iklan yang dilakukan traveloka.com sudah efektif. Disarakan kepada pihak traveloka.com agar memperhatikan faktor Attention, yaitu dengan meningkatkan perhatian terhadap pesan iklan agar lebih menonjol dibandingkan merk lain. Pihak traveloka.com juga hendak memperhatikan hal lain yang dianggap penting dalam meningkatkan keputusan pembelian baik dalam pendekatan komunikasi dan pesan iklan demi keberlangsungan dan menghadapi persingan dengan perusahaan sejenis lainnya.

Adapun saran akademis bagi peneliti selanjutnya yaitu, peneliti lebih lanjut diharapkan menggali variabel yang lain dengan jumlah sampel yang lebih besar agar ditemukan penelitian yang dapat memperkaya hasil penelitian ini. 


\section{Kepustakaan}

Ariesthya, Vannia. 2012. Analisis Efektivitas Iklan dalam Mempengaruhi Keputusan Pembelian Kartu Seluler IM3 versi "IM3 Seru Gratis Gak Abis Abis. Unpublish Skripsi. Bogor: Institut Pertanian Bogor.

Ardi, Maulana Bagus, dan Widya Sastikia. 2018. EPIC Model dan Direct Rating Method: efektivitas Iklan Media Sosial Instagram Batagor Hanimun di Kota Cimahi tahun 2018. Unpublish Skripsi. Bandung: Universitas Telkom.

Badan Pusat Statistika Indonesia. 2020. Hasil Sensus Penduduk 2020. (Online). https://www.bps.go.id/pressrelease/202 1/01/21/1854/hasil-sensus-penduduk2020. html, 29 Januari 2021.

Campbell. 1989. Riset dalam Efektivitas Organisasi. Somamora. Jakarta: Erlangga.

Desel, Aldilah. 2010. Efektivitas Ikln Retail Giant Sun City Sidoarjo (Studi Deskriptif Kuantitatif Efektivitas Iklan Retail Giant Sun City Sidoarjo). Unpublish Skripsi. Surabaya: Univeritas Pembangunan Nasional "Veteran".

Durianto D, Sugiarto, A.W. Widjaja, H. Supratikno. 2003. Inovasi Pasar dengan Iklan Yang Efektif. Jakarta: PT. Gramedia Pustaka Utama.

Franedya, Roy. 2019. Survei: Pengguna Internet di RI Tembus 171.1 Juta Jiwa. (Online).

https://www.cnbcindonesia.com/tech/20 190516191935-37-73041/surveipengguna-internet-di-ri-tembus-17117juta-jiwa, 19 September 2020.

Gunawan, Virto Arby, dkk. 2019. The Determinant Factors of E-Commerce PurchaseDecision in Jakarta and Tangerang. Unpublish Skripsi. Jakarta: Universitas Bina Nusantara.

Gibson, R. F. 1984. Prinsiple of Composite Material Mechanics. New York: Mc Graw Hill.

Ham, Gracella Tita. 2014. Pengukuran Efektivitas Promosi dengan Pendekatan EPIC Model. Studi Kasus pada Konsumen/Pengunjung Malioboro Mall Yogyakarta. Unpublish Skripsi. Yogyakarta: Universitas Sanata Dharma Yogyakarta.
Hasan, Iqbal. 2002. Pokok-Pokok Materi Metodologi Penelitian dan aplikasinya. Jakarta: Ghalia Indonesia.

Hassana, Nur. 2016. Analisis Efektivitas Iklan Online Gojek di Kalangan Pengguna Media Sosial di Kota Makassar. Unpublish Skripsi. Makassar: Universitas Negeri Makassar.

Insights, CB. Mei 2021. Valuasi 5 starup Unicorn Indonesia. (Online). https://databoks.katadata.co.id/datapubl ish/2021/05/27/goto-miliki-valuasitertinggi-di-indonesia, 29 Mei 2021.

Kemp, Simon. 2020. Digital 2020: Indonesia. (Online).

$\mathrm{https}$ :/datareportal.com/reports/digital2020-indonesia, 17 September 2020.

Kharisma, Bungga Annisa. 2012. Analisis Efektivitas Promosi Terhadap BanyaknyaPengunjung Taman Bunga Nusantara Cianjur, Jawa Barat. Unpublish Skripsi. Bogor: Institut Pertanian Bogor.

Kotler, P. dan K.L. Keller. 2007. Manajemen Pemasaran Edisi ke-12 Jilid 1. Jakarta: PT. Indeks. 2008. Manajemen Pemasaran Edisi ke-13 Jilid 1. Jakarta: PT. Indeks.

Kotler, Philip dan Amstrong, Gray. 2008. Dasar-Dasar Pemasaran. Edisi ke-12. Jilid 1. Alih bahas Bob Sabran. Jakarta: Penerbit Erlangga.

Kotler, P. 2009. Manajemen Pemasaran Jilid 1 dan 2. Edisi 12. Jakarta: PT. Indeks.

Lovelock, C.H dan L.K. Wright. 2005. Manajemen Pemasaran Jasa. Jakarta: PT. Indeks.

Morrisan. 2007. Periklanan dan Komunikasi Pemasaran Terpadu. Jakarta: Ramadina Prakarsa.

Muhadjir, Noeng. 1996. Metode Penelitian Kuliatatif. Yogyakarta: Rakate Sarasin.

Paramita, Ni Luh Putu Riska. 2018. Efektivitas Promosi Tiket.com Terhadap Keputusan Pembelian Tiket Pesawat (Sudi Kasus Pembelian Tiket Pesawat Menuju Bali Wisatawan Domestik). Jurnal IPTA. Bali: Universitas Udayana.

Putra, I Gede Cahaya Adi. 2016. Pengaruh harga dan Citra Merek Terhadap Keputusan Pembelian Tiket Maskapai Citilink Oleh Wisatawan Nusantara di 
Bandara Ngurah Rai, Bali. Jurnal IPTA. Bali: Universitas Udayana.

Nugroho, B.A. 2005. Strategi Jitu Memilih Metode Statistika Penelitian dengan SPSS. Yogyakarta: CV Andi Offset.

Rangkuti, F. 2009. Mengukur Efektivitas Program Promosi dan Analisis Kasus Menggunakan SPSS. Jakarta: PT. Gramedia Pustaka Utama.

Santosa, P.B. 2005. Analisis Statistik dengan Microsoft Excel dan SPSS. Yogyakarta: CV Andi Offset.

Shimp, T.A. 2003. Periklanan dan Promosi, Aspek Tambahan Komunikasi Pemasaran Terpadu (Terjemahan). Jakarta: Penerbit Erlangga.

Setiadi, N. 2003. Perilaku Konsumen: Konsep dan Implikasi untuk Strategi dan Penelitian Pemasaran. Jakarta: Kencana.

Sugiyono, 2007. Metode Penelitian Kuantitaif Kualitatif dan $R \& D$. Bandung: Alfabeta 2010. Metode Penelitian Pendidikan Pendekatan Kuantitatif, Kualitatif, dan R\&D. Bandung: Alfabeta 2012. Metode Penelitian Kuantitatif, Kualitatif, dan $R \& D$. Bandung: Alfabeta.

Traveloka. 2020. Tentang Kami. (Online). www.traveloka.com, 13 Agustus 2020.

Tohmatsu, Deloitte Touche. 2019. Pendapatan Iklan Berdasrkan Media. (Online). https://databoks.katadata.co.id/datapubl ish/2019/12/18/iklan-ponsel-bakal-

kalahkan-iklan-televisi, 20 Agustus 2020.

TOP BRAND AWARD. 2020. Top Brand Index Situs Online Booking Tiket Pesawat dan Travel di Indonesia. (Online). https://www.topbrandaward.com/top-brand-

index/?tbi_find=Traveloka.com, $\quad 20$ Agustus 2020.

Umar, H. 2003. Riset Pemasaran dan Perilaku Pemasaran. Jakarta: PT. Gramedia Pustaka Utama.

Wardani, Agustin Setyo. 2019. Jumlah Pengguna Internet di Indonesia Sentuh Angka 171 Juta. (Online). https://www.liputan6.com/tekno/read/39 67287/jumlah-pengguna-internet-diindonesia-sentuh-angka-171-juta, 17 September 2020.
Wulandari, Siti. 2019. Efektivitas Iklan El's Coffee Menggunakan EPIC Model. Unpublish Skripsi. Lampung: Institut Informatif dan Bisnis Darmajaya. 